\title{
Anticancer and Antioxidant Activities of Standardized Whole Fruit, Pulp, and Peel Extracts of Egyptian Pomegranate
}

\author{
Amira Abdel Motaal ${ }^{*, a}$ and Sherif Shaker ${ }^{\mathrm{b}}$ \\ ${ }^{a}$ Pharmacognosy Department, Faculty of Pharmacy, Cairo University, Kasr-El-Ainy St., Cairo 11562, Egypt \\ ${ }^{b}$ Pharmaceutical Research and Development Department, Atos pharma, Sekem, 3 Cairo-Belbeis Road, El Horreya, \\ Cairo, P.B. 2834, Egypt
}

\begin{abstract}
Different parts of the fruit of Punica granatum L. family Punicaceae cultivated in Egypt were extracted and standardized to be assessed for their anticancer and antioxidant properties. An HPLC method was modified and validated for standardization using ellagic acid (EA) as a marker. The $50 \%$ ethanol was proven to be a better solvent for extraction than the $70 \%$ ethanol, as the $50 \%$ hydroalcoholic fruit extract was standardized to contain $5.9 \pm 0.15 \%$ total polyphenols compared to $4.4 \pm 0.35 \%$ in the $70 \%$ hydroalcoholic extract. The $50 \%$ hydroalcoholic extracts of the whole fruit, pulp and peels were standardized to contain $0.3 \pm 0.05,0.02 \pm 0.01$ and $1.9 \pm 0.1 \%$ of EA, respectively. The peel extract showed the highest antioxidant activity $\left(\mathrm{IC}_{50}=0.50 \pm 0.9 \mathrm{mg} / \mathrm{ml}\right.$ ) compared to the other two extracts, as well as, a pronounced anticancer activity against MCF-7 human breast cancer cells and HCT-116 colon cancer cells with IC 50 values of $7.7 \pm$ 0.01 and $9.3 \pm 0.06 \mu \mathrm{g} / \mathrm{ml}$, respectively. The standardized peel extract was formulated into capsules. Here we report the possible use of pomegranate peels, a biological waste product, to develop natural pharmaceutical preparations.
\end{abstract}

Keywords: Anticancer, antioxidant, biowaste, ellagic acid, peels, punica granatum, validation.

\section{INTRODUCTION}

Carcinogenesis is becoming a big load on families and economies. Fruits consumed in our daily diet could be a solution to this burden by providing a chemoprotective or/and chemotherapeutic remedy. Oxidative stress may initiate molecular events in the cancer process, and reduction of oxidative stress may protect against carcinogenesis [1]. Moreover the fruit waste by-products possessing such activities would be a great support to the economy sparing huge sums of money.

Punica granatum L. family Punicaceae is cultivated around the world in subtropical and tropical regions such as in Iran, California, Turkey, Egypt, Italy, India, Chile and Spain. The world pomegranate production amounts to approximately 1,500,000 tons [2], where the peels (pericarp, rind or hull) amounts to approximately $60 \%$ of the pomegranate fruit weight [3]. Pomegranate fruit extracts rich in ellagitannins (ETs) proved their efficacy as antioxidant and anticancer agents, especially against breast and colon cancer [3-6].

Pomegranate peel extracts exhibited marked antioxidant capacity in several studies using unsafe solvents such as methanol and a mixture of methanol, acetone, ethyl acetate and water [7-9].

Knowing that no such studies were performed on Pomegranate growing in Egypt, we decided to carry out a comparative study to assess extracts from different Egyptian

*Address correspondence to this author at the Pharmacognosy Department, Faculty of Pharmacy, Cairo University, Kasr-El-Ainy St., Cairo11562, Egypt; Tel: +2 012 1770823; Fax: +2 25320005;

E-mail: a_motaal@hotmail.com pomegranate compartments, namely the whole fruit, pulp and peels, with the aim of defining an effective standardized extract having a suitable yield to be incorporated into a pharmaceutical preparation as a dietary supplement. Solvents used for extraction were chosen to be safe and suitable for large scale production afterwards.

ETs are the predominant phenolics in pomegranate peel, mesocarp and arils extracts [10].

Upon consumption these ETs are hydrolyzed releasing EA, which is then converted to urolithin derivatives by gut microflora [11]. EA is known for its antioxidant, antiinflammatory and anticarcinogenic properties, besides it is considered as a biomarker for human bioavailability studies involving consumption of ETs containing food, as it is detected in human plasma [12]. For these reasons we chose EA, among several other phenolic compounds present [13], as a bioactive marker for standardization of pomegranate extracts investigated in this study. Validation of the HPLC method used was also performed.

\section{MATERIALS AND METHODS}

\section{Plant Material and Chemicals}

Fresh Pomegranate fruit cultivated in Egypt were obtained from Sekem farms, Belbeis, Egypt. All chemical reagents and extraction solvents were of analytical grade, and all analysis solvents were of HPLC grade. Ellagic acid, diphenyl-1-picrylhydrazyl (DPPH) and gallic acid standards were purchased from Sigma-Aldrich (St. Louis, MO, USA).

\section{Preparation of Pomegranate Extracts}

Fresh pomegranate fruit were collected in October 2008, cut into pieces, blended in $70 \%$ and $50 \%$ ethanol solution. 
Pomegranate fruit were peeled manually where the edible pulp (arils) was blended with 50\% ethanol. The peels were left to dry in the shade, extracted and macerated in $50 \%$ ethanol solution. All extracts were macerated for two days, filtered and the marc macerated for another two days, filtered and concentrated under vacuum at $50{ }^{\circ} \mathrm{C}$. The yields of the extracts were $28 \pm 2.3,14 \pm 1.5$ and $45 \pm 3.2 \%$ for the whole fruit, pulp and peels, respectively, based on dry weight.

\section{Spectrophotometric Determination of Total Polyphenols}

Total polyphenols calculated as gallic acid were determined by the Folin-Ciocalteu method according to the European pharmacopoeia [14], using gallic acid as a standard. Folin-Ciocalteu reagent was purchased from Loba Chemie, Mumbai, India.

\section{Standardization of Pomegranate Extracts by HPLC}

An HPLC method, modified after Gudej and Tomczyk [15], was adopted for the determination of the concentration of ellagic acid in pomegranate different extracts. An Agilent 1100 series HPLC was used, equipped with an Agilent G1311A quaternary pump, a G1314A variable wavelength detector and a G1328A manual injector.

Samples were dissolved in methanol, filtered through PTFE $0.45 \mu \mathrm{m}$ syringe filter (Macherey-Nagel, Germany) and injected into a Hypersil $100 \mathrm{RP}-18,5 \mu \mathrm{m}, 250 \times 4 \mathrm{~mm}$ column. The mobile phase was methanol (solvent A) and $0.5 \%$ orthophosphoric acid in water (solvent B). Gradient elution was carried out at a flow rate of $1.2 \mathrm{ml} / \mathrm{min}$ as follows: $0-5 \min 50$ to $60 \% \mathrm{~A}$ in $\mathrm{B}, 5-8 \mathrm{~min} 60$ to $85 \% \mathrm{~A}$ in $\mathrm{B}$ and $8-10$ min 85 to $50 \% \mathrm{~A}$ in $\mathrm{B}$. Measurements were made with an injection volume of $20 \mu \mathrm{l}$ and UV detection at 254 nm. A standard calibration curve was prepared using different concentrations of ellagic acid in methanol $(1.6,3.2$, $4.8,6.4$ and $8 \mu \mathrm{g} / \mathrm{ml}$ ). Three replicate assays were performed for each sample.

\section{Validation of HPLC Method}

Linearity was determined by injecting five different concentrations of EA standard solution $(1.6-8 \mu \mathrm{g} / \mathrm{ml})$. The accuracy was calculated as the percent recovery of spiked pomegranate extract samples with EA samples at three concentrations $(1.6,3.2$ and $4.8 \mu \mathrm{g} / \mathrm{ml})$. To establish the intra-day and inter-day precision of the method, EA was assayed on one day and three separate days at three different concentrations $(1.6,4.8$ and $8 \mu \mathrm{g} / \mathrm{ml})$. Each was injected in triplicates. Limit of quantitation (LQ) and limit of detection (LD) were determined based on the standard deviation of the response $(\sigma)$ and the slope of the calibration curve (S) according to the following equations [16]:

$$
\begin{aligned}
& \mathrm{LQ}=10(\sigma / \mathrm{S}) \\
& \mathrm{LD}=3.3(\sigma / \mathrm{S})
\end{aligned}
$$

\section{Antioxidant Activity}

The antioxidant activity was assayed using a modified quantitative DPPH assay [17]. DDPH solution was prepared with an HPLC grade methanol at a concentration of $0.004 \%$. Extracts were dissolved in water at a concentration of 0.4 , $0.6,0.8$ and $1 \mathrm{mg} / \mathrm{ml}$, with $100 \mu \mathrm{l}$ of each test solution added to $3 \mathrm{~mL}$ DPPH solution. Blank samples were run using 100 $\mu \mathrm{l}$ water in place of the plant extract. After a $30 \mathrm{~min}$ incubation period at room temperature, the absorbance was measured against a blank at $517 \mathrm{~nm}$. Gallic and ellagic acids were used as positive controls at a concentration of 0.02 , $0.04,0.06,0.08$ and $0.1 \mathrm{mg} / \mathrm{ml}$. Inhibition of free radical in percent $(\mathrm{I} \%)$ was calculated according to this formula: $\mathrm{I} \%=[$ $\left.\left(A_{0}-A_{1}\right) / A_{0}\right] X 100$. Where $A_{0}$ is the absorbance of the control reaction (containing all reagents except the extract), and $A_{1}$ is the absorbance of the extract. Measurements were carried out in triplicates.

\section{Anticancer Activity}

Human breast carcinoma cells (MCF-7) and colon carcinoma cells (HCT-116) obtained from the National Cancer Institute, Cairo, Egypt were used for screening the anticancer activity of the pomegranate extracts using the sulforhodamine B (SRB) colorimetric cytotoxicity assay [18]. The extracts were dissolved in DMSO and tested at concentrations of $1,2,2.5,5$ and $10 \mu \mathrm{g} / \mathrm{ml}$. Doxorubicin was used as a positive control at the same concentration range. Final concentration of DMSO in the culture medium was maintained at $0.1 \%$ to avoid solvent toxicity. Cytotoxicity was expressed as the percent of viable cells relative to cells incubated in the presence of $0.1 \%$ DMSO vehicle control. The concentration of the plant extract inhibiting cell growth by $50 \%$ relative to vehicle control $\left(\mathrm{IC}_{50}\right.$ value) was also determined. Each measurement was performed in triplicate.

\section{Formulation of the Peel Extract}

Pomegranate peel extract was dissolved in least amount of ethanol and loaded on silicon dioxide HDK $® N 20$ (Nünchritz, Germany) in the ratio of $73-75 \%$ (native extract 2-3:1) : 25-27\% (silicon dioxide). The prepared extract (PE) was dried in an oven at $50^{\circ} \mathrm{C}$ and analyzed. Formulation into a capsule (size 0) was achieved by mixing $400 \mathrm{mg}$ of PE with $65 \mathrm{mg}$ micro-crystalline cellulose 101, $20 \mathrm{mg}$ talc and $15 \mathrm{mg}$ magnesium stearate.

\section{RESULTS AND DISCUSSION}

\section{HPLC Standardization of Pomegranate Extracts}

A $50 \%$ and a $70 \%$ hydroethanolic extracts of pomegranate whole fruit were prepared and analyzed spectrophotometrically to determine the better solvent for extraction. The $50 \%$ hydroalcoholic extract proved to contain $5.9 \pm 0.15 \%$ total polyphenols calculated as gallic acid, compared to $4.4 \pm 0.35 \%$ in the $70 \%$ extract. Hydroalcoholic extracts $(50 \%)$ of the whole fruit, pulp and peels were prepared and standardized using an HPLC method, modified after Gudej and Tomczyk [15]. Knowing the antioxidant, anti-inflammatory and anticarcinogenic properties of EA, it was chosen as a bioactive marker for standardization of these extracts. EA peak appeared at a retention time of $5.9 \mathrm{~min}$. The peel extract was standardized to contain $1.9 \pm 0.01 \%$ of EA, while the fruit and pulp extracts contained $0.3 \pm 0.05$ and $0.02 \pm 0.01 \%$, respectively Fig. (1). The calibration curve showed good linearity for EA in the range of $1.6-8 \mu \mathrm{g} / \mathrm{ml}$, with a correlation co-efficient $\left(\mathrm{R}^{2}\right)$ of 0.998 Fig. (2). The percent recovery was within the range of $98.0-102.0 \%$ showing the accuracy of the method. The intra- and inter-day variation of the method was carried out and the low values of relative standard deviation (RSD $<2 \%$ ) within a day and day to day variations revealed that this method is precise (Table 1). The minimum 


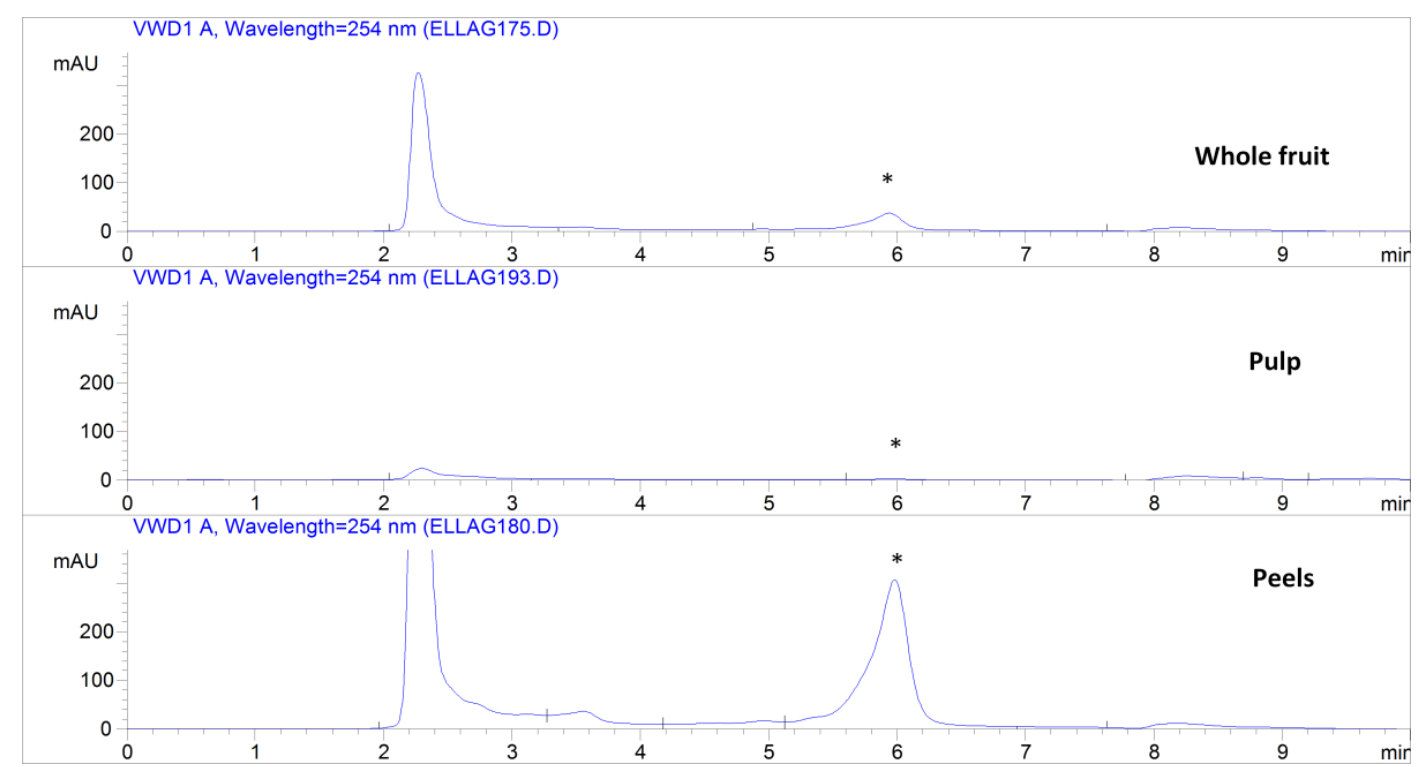

Fig. (1). HPLC chromatograms of 50\% ethanolic extracts of pomegranate fruit, pulp and peels. Peaks highlighted with an asterisk represent that of ellagic acid (Rt at $5.9 \mathrm{~min}$ ). Chromatographic conditions are described under "Materials and Methods".

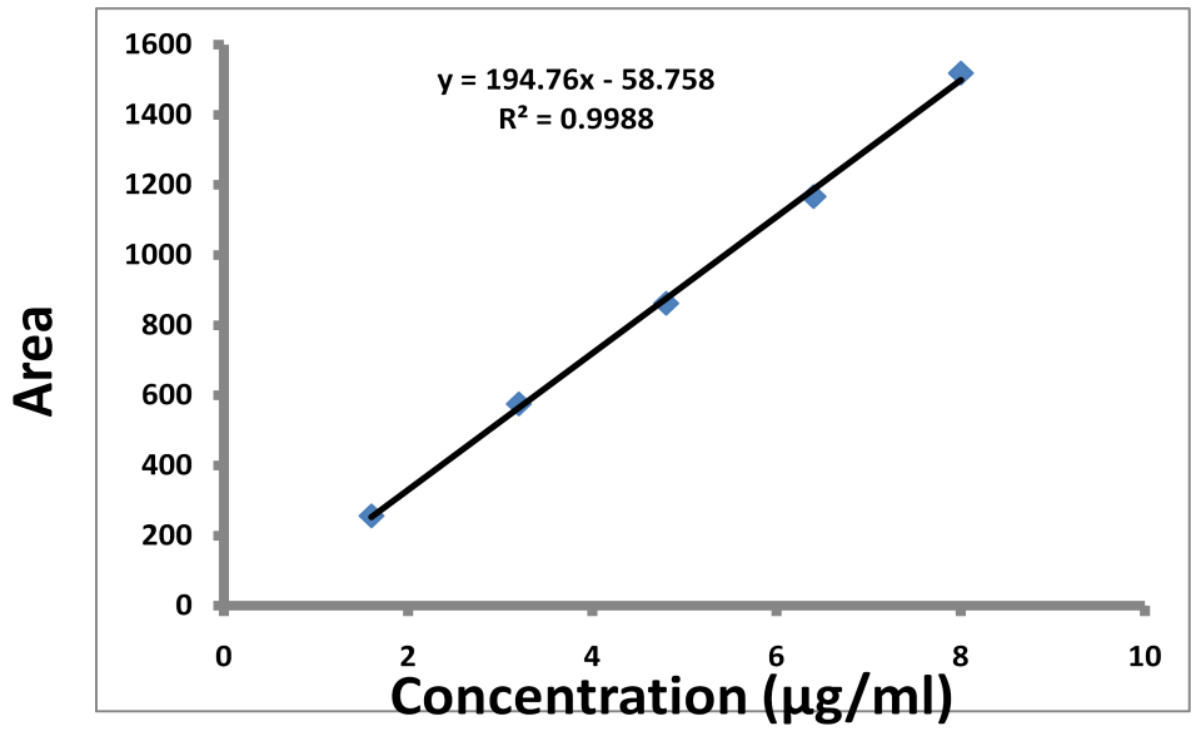

Fig. (2). Calibration curve of EA using an HPLC method modified after Gudej and Tomczyk [15].

concentration levels at which the analyte can be reliably detected (LD) and quantified (LQ) were found to be 0.116 and $0.354 \mu \mathrm{g} / \mathrm{ml}$, respectively (Table 1). The LD and LQ of an HPLC method, previously developed by Panichayupakarananta [9] for standardization of pomegranate peel extract using also EA, were 1.00 and $2.50 \mu \mathrm{g} / \mathrm{ml}$, respectively. His percent recovery was $98.5 \%$ versus $99.57 \pm$ $1.017 \%$ achieved by our method. The EA peak did not interfere with any other peak in the extract samples Fig. (1), which indicated the specificity of the proposed method.

\section{Formulation of Peel Extract}

PE was used as the raw material for preparation of pomegranate capsules. It was characterized as a yellowish brown powder, standardized to contain $1.5 \pm 0.05 \%$ of EA. The prepared capsules were opaque brown hard gelatin capsules having a filling weight of $500 \pm 10 \%$, analyzed to contain $1.4 \pm 0.07 \%$ of EA and $8.5 \pm 0.25 \%$ of total polyphenols. Disintegration time of the capsules was $3 \mathrm{~min}$.

\section{Antioxidant Activity of Pomegranate Extracts}

Pomegranate standardized extracts were assessed for their capacity to scavenge DDPH free radical along with gallic acid as a positive control. The antioxidant activity data are presented in Table 2 , in terms of $\mathrm{IC}_{50} \pm \mathrm{SD}(\mathrm{n}=3)$, which is the concentration in $\mathrm{mg} / \mathrm{ml}$ causing $50 \%$ inhibition of the free radical. The $50 \%$ ethanolic extract of the peels standardized to contain the highest percent of EA (1.9 \pm $0.1 \%)$ exhibited a pronounced antioxidant activity $\left(\mathrm{IC}_{50}=\right.$ $0.50 \pm 0.9 \mathrm{mg} / \mathrm{ml})$ compared to the fruit $(0.3 \pm 0.05 \% \mathrm{EA})$ and pulp $\left(0.02 \pm 0.01 \%\right.$ EA) extracts showing an $\mathrm{IC}_{50}$ of 1.09 $\pm 0.5 \mathrm{mg} / \mathrm{ml}$ and $13.6 \pm 0.8 \mathrm{mg} / \mathrm{ml}$, respectively. These results show a direct correlation between the EA content in pomegranate extracts and its ability in quenching free 
Table 1. Results of HPLC Method Validation Used for Standardization of Pomegranate Extracts

\begin{tabular}{|l|l|}
\hline Range & $1.6-8 \mu \mathrm{g} / \mathrm{ml}$ \\
\hline Linearity & $\begin{array}{l}\text { correlation coefficient: } 0.998 \\
\text { slope: } 194.75 \\
\text { Intercept: }-58.7583\end{array}$ \\
\hline Accuracy & Recovery: $99.57 \pm 1.017 \%$ \\
\hline Precision & $\begin{array}{l}\text { Intra-day RSD } 1.72 \% \\
\text { Inter-day RSD } 1.86 \%\end{array}$ \\
\hline Limit of Detection & $0.116 \mu \mathrm{g} / \mathrm{ml}$ \\
\hline Limit of Quantitation & $0.354 \mu \mathrm{g} / \mathrm{ml}$ \\
\hline Specificity & No interference with other peaks \\
\hline
\end{tabular}

radicals. The contents of total phenolics in pomegranate peel extract was reported to be 10 -fold as much as its content in the pulp extract, which causes its stronger antioxidant ability [19]. It was also mentioned that the EA content and the antioxidant activity of the ethyl acetate fraction separated from the crude peel extract using water and ethyl acetate partition was higher than that of the crude extract [9].

Table 2. Antioxidant Activity Assayed by DPPH Test of Pomegranate Extracts

\begin{tabular}{|c|c|}
\hline Extract & $\mathbf{I C}_{\mathbf{5 0}}(\mathbf{m g} / \mathbf{m l}) \pm \mathbf{S D}$ \\
\hline \hline Whole fruit & $1.09 \pm 0.5$ \\
\hline Peels & $0.50 \pm 0.9$ \\
\hline Pulp & $13.6 \pm 0.8$ \\
\hline Gallic acid & $0.05 \pm 0.4$ \\
\hline Ellagic acid & $0.08 \pm 0.5$ \\
\hline
\end{tabular}

Activity is expressed as $\mathrm{IC}_{50} \pm \mathrm{SD}(\mathrm{n}=3)$, which is the concentration $(\mathrm{mg} / \mathrm{ml})$ causing $50 \%$ inhibition of the free radical. Whole fruit and peel extracts were tested at $0.4,0.6$, 0.8 and $1 \mathrm{mg} / \mathrm{ml}$, pulp extract at $4,6,8$ and $10 \mathrm{mg} / \mathrm{ml}$ while the positive controls (gallic and ellagic acids) at $0.04,0.06,0.08$ and $0.1 \mathrm{mg} / \mathrm{ml}$.

\section{Anticancer Activity of Pomegranate Extracts}

The anticancer activity of pomegranate fruit, peels and pulp extracts standardized to their EA content was assessed. Cytotoxicity was tested against MCF-7 cell line (human breast carcinoma) and HCT-116 cell line (human colon carcinoma) along with doxorubicin as a positive control. The dose-dependent cytotoxic activity of the three standardized extracts are presented in Figs. (3 and $\mathbf{4})$. The anticancer activity against both cell lines increased by increasing the extract concentrations from 1 to $10 \mu \mathrm{g} / \mathrm{ml}$ for all three extracts. The pomegranate peel extract showed a pronounced cytotoxic activity against MCF-7 cells compared to the other two extracts at a concentration of $10 \mu \mathrm{g} / \mathrm{ml}$ Fig. (3), confirmed by the least $\operatorname{IC}_{50}(7.7 \pm 0.01 \mu \mathrm{g} / \mathrm{ml})$ (Table 3). On the other hand, the anticancer activity of the fruit extract against HCT-116 colon cells was the most prominent revealed by an $\mathrm{IC}_{50}$ of $4.8 \pm 0.02 \mu \mathrm{g} / \mathrm{ml}$ followed by the pulp extract $\left(\mathrm{IC}_{50}=6.1 \pm 0.04 \mu \mathrm{g} / \mathrm{ml}\right)$. It was previously reported that the ellagitannins and their intestinal bacterial metabolites, urolithins, released in the colon upon consumption of pomegranate juice could potentially diminish the risk of colon cancer development, by inhibiting cell proliferation and inducing apoptosis [5]. Also pomegranate ET-derived compounds especially urolithin B have potential for the prevention of estrogen-responsive breast cancers by significantly inhibiting testosteroneinduced MCF-7 cell proliferation [4]. However according to the presented data, EA content alone does not reflect the potency of the anticancer activity as the pomegranate fruit is rich in several other cytotoxic compounds as sterols, hydroxybenzoic acids, catechins, epicatechins, anthocyanidins and flavonoids which could also contribute to the anticancer activity [3]. Future studies need to address the possible mechanisms of anticancer activities of the different extracts and their corresponding compounds.

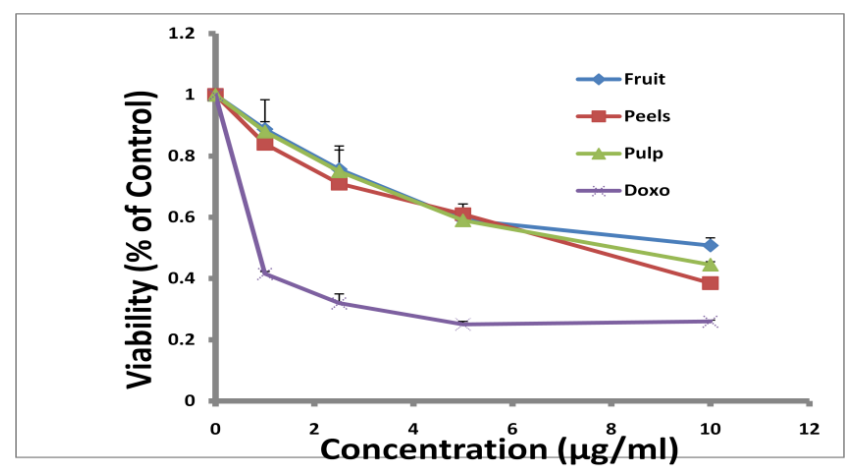

Fig. (3). Dose-dependent cytotoxicity of pomegranate extracts on MCF-7 breast cancer cells using the SRB assay. Viability is calculated as a percent of control (cells incubated with $0.1 \%$ DMSO). Results are the average of three independent experiments \pm SD ( $n=3$ ). Doxorubicin (Doxo) was used as a positive control.

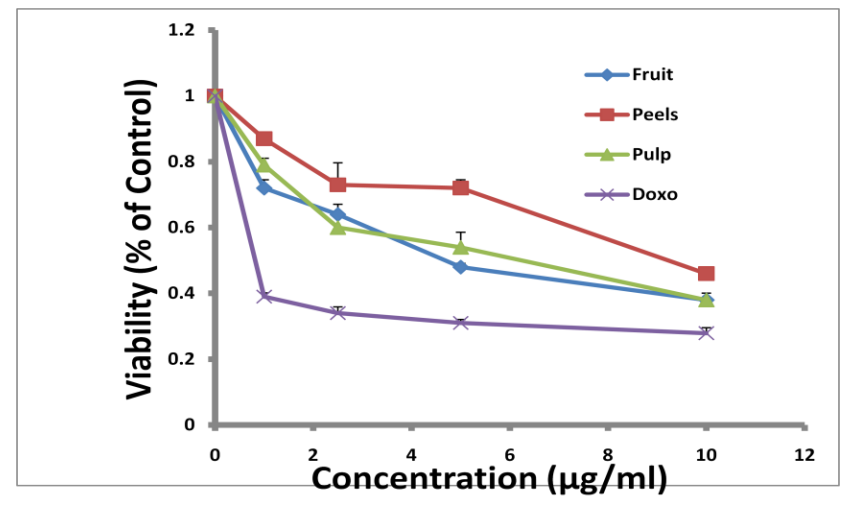

Fig. (4). Dose-dependent cytotoxicity of pomegranate extracts on HCT-116 colon cancer cells using the SRB assay. Viability is calculated as a percent of control (cells incubated with $0.1 \%$ DMSO). Results are the average of three independent experiments $\pm \mathrm{SD}(\mathrm{n}=3$ ). Doxorubicin (Doxo) was used as a positive control.

\section{CONCLUSION}

This study indicates that pomegranate peel extract of Egyptian pomegranate collected in October, standardized to contain $1.9 \pm 0.1 \%$ of EA, has a potential as an antioxidant 
Table 3. Cytotoxicity of Pomegranate Extracts on Human MCF-7 and HCT-116 Carcinoma

\begin{tabular}{|c|c|c|}
\hline \multirow{2}{*}{ Extract } & \multicolumn{2}{|c|}{$\mathbf{I C}_{\mathbf{5 0}} \boldsymbol{\mu g} / \mathbf{m l} \pm \mathbf{S D}$} \\
\cline { 2 - 3 } & $\mathbf{M C F - 7}$ & HCT-116 \\
\hline \hline Whole fruit & $9.9 \pm 0.03$ & $4.8 \pm 0.02$ \\
\hline Peels & $7.7 \pm 0.01$ & $9.3 \pm 0.06$ \\
\hline Pulp & $7.9 \pm 0.05$ & $6.1 \pm 0.04$ \\
\hline Doxorubicin & $0.7 \pm 0.01$ & $0.69 \pm 0.01$ \\
\hline
\end{tabular}

Cytotoxicity is expressed as $\mathrm{IC}_{50} \pm \mathrm{SD}(\mathrm{n}=3)$, which is the concentration of the plant extract inhibiting cell growth by $50 \%$ relative to cells incubated in the presence of $0.1 \%$ DMSO vehicle control.

compared to the whole fruit and pulp extracts. EA could be used as a biomarker for pomegranate dietary supplements used as antioxidants. Further studies are required to assess the EA content of pomegranate peel extract and its corresponding activities at different growing seasons in Egypt.

\section{REFERENCES}

[1] Hwang, E.S.; Bowen, P.E. DNA damage, a biomarker of carcinogenesis: its measurement and modulation by diet and environment. Crit. Rev. Food Sci. Nutr., 2007, 47(1), 27-50.

[2] FAOSTAT-FAO. Statistical database. Food and Agriculture Organization of the United Nations, Codex Alimentarius Commision: Tunis, Tunesia. http://www.fao.org. (Accessed May 23, 2010).

[3] Lansky, E.P.; Newman, R.A. Punica granatum (pomegranate) and its potential for prevention and treatment of inflammation and cancer. J. Ethnopharmacol., 2007, 109(2), 177-206.

[4] Adams, L.S.; Zhang, Y.; Seeram, N.P.; Heber, D.; Chen, S. Pomegranate ellagitannin-derived compounds exhibit antiproliferative and antiaromatase activity in breast cancer cells in vitro. Cancer Prev. Res. (Phila Pa), 2010, 3(1), 108-13.

[5] Kasimsetty, S.G.; Bialonska, D.; Reddy, M.K.; Ma, G.; Khan, S.I.; Ferreira, D. Colon cancer chemopreventive activities of pomegranate ellagitannins and urolithins. J. Agric. Food Chem., 2010, 58(4), 2180-7.

[6] Sharma, M.; Li, L.; Celver, J.; Killian, C.; Kovoor, A.; Seeram, N.P. Effects of fruit ellagitannin extracts, ellagic acid, and their colonic metabolite, urolithin A, on Wnt Signaling. J. Agric. Food Chem., 2010, 58(7), 3965-9.

[7] Ghasemian, A.; Mehrabian, S.; Majd, A. Peel extracts of two Iranian cultivars of pomegranate (Punica granatum) have antioxidant and antimutagenic activities. Pakistan J. Biol. Sci., 2006, 9(7), 1402-5.

[8] Negi, P.S.; Jayaprakasha, G.K.; Jena, B.S. Antioxidant and antimutagenic activities of pomegranate peel extracts. Food Chem., 2002, 80, 393-7.

[9] Panichayupakarananta, P.; Issuriya, A.; Sirikatitham, A.; Wang, W. Antioxidant assay-guided purification and LC determination of ellagic acid in pomegranate peel. J. Chromatogr. Sci., 2010, 48(6), 456-9.

[10] Fischer, U.A.; Carle, R.; Kammerer, D.R. Identification and quantification of phenolic compounds from pomegranate (Punica granatum L.) peel, mesocarp, aril and differently produced juices by HPLC-DAD-ESI/MS ${ }^{n}$, Food Chem., 2011, doi: 10.1016/j.foodchem.2010.12.156

[11] Seeram, N.P.; Aronson, W.J.; Zhang, Y.; Henning, S.M.; Moro, A.; Lee, R.P.; Sartippour, M.; Harris, D.M.; Rettig, M.; Suchard, M.A.; Pantuck, A.J.; Belldegrun, A.; Heber, D. Pomegranate ellagitanninderived metabolites inhibit prostate cancer growth and localize to the mouse prostate gland. J. Agric. Food Chem., 2007, 55, 7732-7.

[12] Seeram, N.P.; Lee, R.; Heber, D. Bioavailability of ellagic acid in human plasma after consumption of ellagitannins from pomegranate (Punica granatum L.) juice. Clin. Chim. Acta., 2004, 348, 63-8.

[13] Fischer, U. A.; Carle, R.; Kammerer, D. R. Identification and quantification of phenolic compounds from pomegranate (Punica granatum $L$.) peel, mesocarp, aril and differently produced juices by HPLC-DAD-ESI/MSn. Food Chem., 2011, 127, 807-21.

[14] Druckerei C.H. European Pharmacopoeia, $4^{\text {th }}$ ed.; Beck: Nördlingen, Germany, 2002, p. 187.

[15] Gudej, J.; Tomczyk, M. Determination of flavonoids, tannins and ellagic acid in leaves from Rubus L. species. Arch. Pharm. Res., 2004, 27(11), 1114-9.

[16] ICH, "Validation of Analytical Procedures: Methodology," Proceeding of the International Conference on Harmonization, Geneva, 1996.

[17] Shimada, K.; Fujikawa, K.; Yahara, K.; Nakamura, T. Antioxidative properties of xanthan on the autoxidation of soybean oil in cyclodextrin emulsion. J. Agric. Food Chem., 1992, 40, 9458.

[18] Skehan, P.; Storeng, R.; Scudiero, D.; Monks, A.; McMahon, J.; Vistica, D.; Warren, J.T.; Bokesch, H.; Kenney, S.; Boyd, M.R. New colorimetric cytotoxicity assay for anticancer-drug screening. J. Natl. Cancer Inst., 1990, 82(13),1107-12.

[19] Li, Y.; Guo, C.; Yang, J.; Wei, J.; Xu, J.; Cheng, S. Evaluation of antioxidant properties of pomegranate peel extract in comparison with pomegranate pulp extract. Food Chem., 2006, 96(2), 254-60.

() Motaal and Shaker; Licensee Bentham Open.

This is an open access article licensed under the terms of the Creative Commons Attribution Non-Commercial License (http://creativecommons.org/licenses/by-nc/3.0/) which permits unrestricted, non-commercial use, distribution and reproduction in any medium, provided the work is properly cited. 